\title{
Sabores locais: memórias e narrativas da gastronomia na cidade de Florianópolis/SC
}

\author{
Local flavors: memories and gastronomy narratives in the city of Florianópolis/SC
}

\section{Gisele Palma Moser}

\author{
Universidade Federal de Santa Catarina - UFSC - Florianópolis - Santa Catarina - Brasil
}

\section{Gláucia de Oliveira Assis}

\author{
Universidade Estadual de Santa Catarina - UDESC - Florianópolis - Santa Catarina - Brasil
}

\begin{abstract}
Resumo: Este trabalho tem como objetivo principal problematizar a cultura alimentar presente na cidade de Florianópolis, capital de Santa Catarina, e dar visibilidade aos modos de saber e fazer de seus moradores, além de buscar compreender os usos destas tradições voltadas para o turismo. A discussão será realizada numa abordagem interdisciplinar ao dialogar a partir de diferentes perspectivas disciplinares, buscando encontrar pontos de reflexão sobre a realidade apresentada. Utilizando a metodologia da História Oral, as memórias e as narrativas de moradores revelam a história e o modo de preparo de pratos tradicionais, como a "tainha escalada" e o "pastel de berbigão", considerados bens imateriais representativos de uma determinada cultura. Os relatos indicam a presença de traços oriundos da cultura portuguesa permeados por outras influências, assim como os modos de fazer incorporaram alterações ao longo do tempo. Nas falas dos entrevistados, os fazeres apresentam expressões, tais como "quando minha mãe fazia" ou "quando minha avó ensinou para minha mãe", que expressam as permanências e as transformações no fazer das práticas culinárias nos dias atuais. O preparo destes pratos é mantido como uma tradição nas famílias, sendo transmitido a cada geração através do convívio no fazer e do saber por meio de uma cultura oral. Por outro lado, a gastronomia à base de frutos do mar encontrada nos restaurantes da cidade aponta uma descaracterização desta tradição, voltando-se para o turismo e para o uso do patrimônio cultural como uma mercadoria. Neste contexto, a cidade vem se destacando como a principal produtora de ostras e mexilhões para o mercado nacional. Conhecer a história destes alimentos e o preparo dos pratos conforme criados e ensinados pelos mais antigos permite compreender a cidade e a sociedade onde estes são desenvolvidos.
\end{abstract}

Palavras-chave: Turismo. Patrimônio imaterial. Florianópolis.

Abstract: This work has as main objective to discuss the food culture present in the city of Florianópolis, capital of Santa Catarina, and give visibility to the ways of knowing and making its residents, and seek to understand the uses of these traditions geared for tourism. The discussion will be held in an interdisciplinary approach to dialogue from different disciplinary perspectives, seeking to find points of reflection on the reality presented. Using the methodology of oral history, memories and residents narratives reveal the history and method of preparation of traditional dishes, such as "mullet escala" and "cockle pastel", considered representative intangible assets of a particular culture. Reports indicate the presence of traces coming from Portuguese culture permeated by other influences, as well as methods of making incorporated changes over time. In the interviews, the doings have expressions such as "when my mother did" or "when my grandmother taught my mother", that express the continuities and transformations in to the culinary practices today. The preparation of these dishes is kept as a tradition in families, being transmitted to each generation through the living in the making and knowledge through an oral culture. On the other hand, the cuisine to fruit-based sea found in restaurants in the city points to a mischaracterization of this tradition, turning to tourism and the use of cultural heritage as a commodity. In this context, the city has emerged as the leading producer of oysters and mussels to the 
domestic market. Knowing the history of these foods and the preparation of the dishes as created and taught by older allows us to understand the city and the society in which they are developed.

Keywords: Tourism. intangible heritage. Florianópolis.

Ágora [ISSN 1982-6737]. Santa Cruz do Sul, v. 18, n. 1, p. 57-67, jan./jun. 2016.

http://online.unisc.br/seer/index.php/agora/index 


\section{Introdução}

A cidade de Florianópolis, hoje com 469,690 mil $^{1}$ habitantes, capital do estado de Santa Catarina, está localizada na região sul do Brasil. Apesar de ser conhecida frequentemente como uma ilha, chamada de Ilha de Santa Catarina, a cidade é composta por uma parte territorial continental, com treze quilômetros quadrados, e a maior parte insular, compreendendo 420 quilômetros quadrados. Por ser cercada pelo mar, boa parte da cultura alimentar tradicional está baseada nos produtos de origem marinha, mesclada com influências diversificadas diante da presença de diferentes povos que habitaram/habitam a região. Nos últimos anos a cidade vem apresentando um grande crescimento populacional $^{2}$ até chegar à marca atual de mais de um milhão de habitantes ao considerarmos a região da Grande Florianópolis ${ }^{3}$, visto que estes municípios interagem cotidianamente através dos empregos e serviços oferecidos na capital. Dos atuais moradores na cidade de Florianópolis, 51,71\% são nascidos em outras cidades, conforme aponta o Censo Demográfico de 2010, realizado pelo Instituto Brasileiro de Geografia e Estatística (IBGE) ${ }^{4}$.

Com o objetivo de problematizar esta cultura alimentar diversificada, buscamos apresentar neste artigo pratos tradicionais que integram a culinária praticada na região, assim como compreender os

\footnotetext{
1 População estimada segundo IBGE 2015. Disponível em: <http://cod.ibge.gov.br/4J6>. Acesso em 7 jun. 2016.

2 Em 1980, Florianópolis contava com 187.871 habitantes, chegando em 2000 com 342.315 habitantes. Os últimos dados divulgados, em 2010, contabilizaram uma população de 421.240 habitantes. Censo Demográfico IBGE 1980 e 2000. Coleção digital. Sinopse do Censo Demográfico 2010. Disponível em: $<$ www.censo2010.ibge.gov.br/sinopse/index.php?uf=42\&dados= 1>. Acesso em 24 nov. 2011.

3 Dados IBGE - Censo Demográfico 2010 indicam a Grande Florianópolis com 1.012.233 habitantes. De acordo com a Associação dos Municípios da Grande Florianópolis, este conglomerado é composto por: Águas Mornas, Alfredo Wagner, Angelina, Anitápolis, Antônio Carlos, Biguaçu, Canelinha, Florianópolis, Garopaba, Governador Celso Ramos, Leoberto Leal, Major Gercino, Nova Trento, Palhoça, Paulo Lopes, Rancho Queimado, Santo Amaro da Imperatriz, São Bonifácio, São João Batista, São José, São Pedro de Alcântara e Tijucas.

${ }^{4}$ Dados do Instituto Brasileiro de Geografia e Estatística (IBGE), 2010. Disponível em: <www.ibge.gov.br/>.
}

usos destas tradições voltadas para o turismo. Dois pratos - tainha escalada e pastel de berbigão - foram selecionados por serem considerados representativos de uma cultura culinária local, sendo frequentemente encontrados em restaurantes da cidade à base de frutos do mar. Duas famílias nos receberam em seus restaurantes e concederam os seus testemunhos, além de mostrarem, passo a passo, como são elaborados os pratos.

A pesquisa foi desenvolvida utilizando a História Oral como um procedimento metodológico "que busca, pela construção de fontes e documentos, registrar, através de narrativas induzidas e estimuladas, testemunhos, versões e interpretações sobre a História em suas múltiplas dimensões: factuais, temporais, espaciais, conflituosas, consensuais" (DELGADO, 2006, p.15). As entrevistas foram feitas com gravações em vídeo e posteriormente transcritas para a forma textual, para que orientassem as análises inseridas neste trabalho. Por cultura oral compreendemos um modo de ser, se comportar e fazer as atividades do dia a dia, em que os mais antigos ensinam aos mais novos através de argumentos orais, elaborando seus discursos, onde as identidades são significadas e ressignificados situando os sujeitos do lugar. $O$ roteiro das entrevistas foi elaborado tomando como base o questionário de identificação de "Ofícios e Modos de Fazer - Gastronomia" que compõe as fichas de inventário do projeto "Identidades", disponibilizado pela Diretoria de Patrimônio da Fundação Catarinense de Cultura de Santa Catarina ${ }^{5}$, o qual engloba questões referentes ao histórico do bem, descrição, adaptações da receita, responsáveis por sua continuidade, relação com o comércio, curiosidades em geral relacionadas ao bem, a sua receita, ingredientes utilizados e modos de fazer.

\footnotetext{
5 O projeto "Identidades" visa à regionalização e municipalização do reconhecimento e valorização do patrimônio cultural catarinense. Apostila Patrimônio Imaterial - Como Identificar, Inventariar e Proteger o Patrimônio. Florianópolis: Fundação Catarinense de Cultural, 2008.
} 
2 Patrimônios imateriais e identidades: "tainha escalada" e "pastel de berbigão"

A partir das memórias e narrativas dos moradores acessamos os modos de fazer enraizados no cotidiano das comunidades da região, neste estudo, através do preparo dos pratos tainha escalada ${ }^{6}$ e pastel de berbigão ${ }^{7}$.

Luiz Carlos de Souza, 50 anos, nascido e criado na mesma localidade em que mora até hoje, no Norte da Ilha de Santa Catarina, cidade de Florianópolis, atua na cozinha de um restaurante em que é proprietário. Ele indica a tainha escalada como um prato tradicional de sua cultura e segue a maneira simples de preparar o peixe, como aprendeu com sua mãe: escalado, temperado com sal e limão. Luiz costuma servir este prato em seu restaurante, principalmente durante a temporada de verão, acompanhado de um pirão de peixe. Enquanto ele prepara a receita na cozinha do restaurante, quem narra a história é a sua esposa: Ana Ester, 42 anos, nascida em São Paulo, região sudeste do país. Ela conta que logo teve que se adaptar aos costumes locais e participar das atividades diárias da família de seu esposo. Os barcos chegavam à noite e Ana ajudava a carregar os balaios cheios de peixes para serem lavados e deixados em uma bacia com água durante a noite. De manhã bem cedo, por volta das cinco horas, sua sogra iniciava o procedimento de escalar o peixe. Ana explica como era o processo: os peixes eram colocados sobre uma folha de bananeira, abertos ao meio e pendurados pela extremidade, amarrados por um fio de cipó, em uma espécie de varal feito com bambus. Ali os peixes ficavam

\footnotetext{
6 A tainha é um peixe que pertence à família Mugilidae, encontrada em águas tropicais e subtropicais de todo o mundo, desenvolve-se em lagoas e estuários (ambientes entre o rio e o mar) e migra para o mar em cardumes para desovar. A pesca da tainha é considerada um importante recurso econômico no litoral catarinense, realizada tanto com frota artesanal quanto industrial (HERBST, 2013)

7 O berbigão é um molusco bivalve marinho, chamado Anomalocardia brasiliana, nativo do Brasil e amplamente encontrado ao longo de toda a costa brasileira, que habita áreas rasas lodosas e é coletado manualmente ou com auxílio de ferramentas rudimentares. As conchas deste molusco podem ser encontradas nos sambaquis, sítios arqueológicos localizados no litoral, que indicam a utilização na alimentação das populações que habitaram a região há mais de sete mil anos (BELEM, 2012).
}

expostos ao sol de dois a três dias, sendo recolhidos à noite para não pegar sereno. Depois de secos eram guardados para as preparações culinárias. Ana Ester lembra de algumas variações de preparos que sua sogra fazia com os peixes, ensopadinho e grelhado, conforme ela narra:

(...) alguns ela desfiava e fazia ensopadinho, porque ele ficava sequinho, e era o que eu gostava de comer. (...) Outros ela fazia na chapa, tinha umas grelhas, que eles arrancavam aquela parte redonda do fogão à lenha, e a grelha ficava bem ali. Aí ela pegava aqueles peixes secos e colocava na grelha, então ela virava ele e ficava todo douradinho amarelinho.

$\mathrm{Na}$ outra ponta da Ilha de Santa Catarina vive Zilá Pereira, 64 anos, que também é proprietária de um restaurante. Nascida, criada e moradora do Sul da ilha, ela diz que o pastel de berbigão é o mais vendido desde o início do seu restaurante, há mais de 30 anos. Ao ser questionada se este seria um prato tradicional em sua família, Zilá diz que não se recorda. Aos poucos, enquanto prepara o refogado que servirá de recheio para o pastel, ela se lembra de sua infância e conta que foi criada comendo ostras. Utilizando panelas de inox bem polidas sobre um fogão moderno, Zilá adiciona ao preparo o berbigão, que já foi comprado limpo e sem casca. E ela diz: "Olha, essa receita na verdade... ensopar o berbigão foi com a minha mãe (que aprendi). O pastel já não foi bem com ela, porque naquela época não sei se eles faziam pastel. (...) A do restaurante, que eles fazem, foi coisa que ficou minha, né"9.

Nas falas citadas, os fazeres apresentam expressões que remetem às permanências e às transformações no fazer, nas sociabilidades e no modo de viver. Podemos dizer que a gastronomia edificada na cultura local faz parte da cultura da cidade e da identidade dos que ali vivem. As modificações, tanto no preparo como nos

\footnotetext{
8 Entrevista realizada em 2010 por Gisele Palma Moser, Daniela Xikota e Matheus Santiago para a elaboração do vídeo documentário "Sabores da Tradição: modos de fazer na gastronomia da Ilha de Santa Catarina" como parte integrante do estudo da disciplina de Patrimônio Cultural, do curso de História, da Universidade do Estado de Santa Catarina (Udesc).

${ }^{9}$ Idem.
} 
ingredientes, fazem parte do que se considera um bem cultural vivo, que se transforma com o passar do tempo. Um bem imaterial rico justamente por essa diversidade e multiplicidade que transmite uma tradição às gerações seguintes, havendo a manutenção do bem como parte da cultura.

Nos relatos dos viajantes que aqui estiveram no século XIX encontram-se registros sobre a culinária de Desterro (antiga nomenclatura de Florianópolis que vigorou até 1894). Georg Heinrich von Langsdorff ${ }^{10}$, por exemplo, ao estudar o litoral catarinense relatou "aspectos da cultura e dos hábitos locais, como alimentar-se de pirão d'água (farinha de mandioca com água fervida), feijão cozido com peixe" (MURR, 1997, p. XLII) e ainda demonstrou-se espantado com o hábito de comer com as mãos. As práticas culinárias atravessaram os séculos e continuam a fazer parte dos saberes e fazeres da cultura local. Podemos perceber no relato de Luiz, como essa tradição é mantida, repassada e reinventada.

No preparo da tainha, Luiz afirma que antigamente o processo era artesanal, salgava-se o peixe e depois tinha que expô-lo ao sol para sua conservação e o preparo era feito no fogão à lenha. Hoje, o peixe sai da rede do pescador (ou do freezer), cortado, temperado e segue direto para a chapa do fogão a gás. Da mesma forma, Zilá diz alterou o preparo da massa do pastel, que antigamente era feito no "muque", como ela conta, misturando água, farinha e ovos e amassando tudo com as mãos. Hoje, ela prefere comprar a massa pronta, pela facilidade e agilidade na montagem do prato. Tais modificações realizadas no processo, tanto no preparo como nos ingredientes, certamente alteram o sabor da receita, porém isso nos indica que é um bem cultural em movimento, que permanece sendo utilizado e que se adapta às novas realidades. Assim, uma receita preparada há mais de cinquenta anos permanece presente, e, neste sentido, as suas transformações podem ser consideradas como adaptações para a manutenção do bem cultural.

\footnotetext{
${ }^{10} \mathrm{O}$ naturalista alemão Georg Heinrich von Langsdorff chefiou a chamada "Expedição Langsdorff", à serviço da Rússia, realizada entre 1822 e 1829, pelo território brasileiro
}

A discussão sobre o patrimônio imaterial no Brasil ganhou espaço a partir da Constituição Federal de 1988, quando a preservação cultural recebeu um conceito mais abrangente de "bem cultural". O artigo 216 da Constituição diz que:

Constituem patrimônio cultural brasileiro os bens de natureza material e imaterial, tomados individualmente ou em conjunto, portadores de referência à identidade, à ação e à memória dos diferentes grupos formadores da sociedade brasileira, nos quais se incluem:

I - as formas de expressão;

I - as formas de expressão;

II - os modos de criar, fazer e viver;

II - os modos de criar, fazer e viver;

III - as criações científicas, artísticas e tecnológicas;

IV - as obras, objetos, documentos, edificações e demais espaços destinados às manifestações artístico-culturais;

$\mathrm{V}$ - os conjuntos urbanos e sítios de valor histórico, paisagístico, artístico, arqueológico, paleontológico, ecológico e científico. (ARTIGO 216, CONSTITUIÇÃO FEDERAL BRASILEIRA, 1988)

Conforme apontam Lucas dos Santos Roque e Maria Helena Cunha (2014, p.11), nas últimas décadas, as políticas públicas de preservação do patrimônio cultural brasileiro permitiram um avanço com a ampliação da noção de Patrimônio Cultural. Passou-se a considerar também as dimensões natural e imaterial das manifestações culturais, o que gerou a necessidade de novos instrumentos e de legislações específicas para garantir a salvaguarda destes bens. Entre eles, o Programa Nacional do Patrimônio Imaterial, vinculado ao Ministério da Cultura, criado em 4 de agosto de 2000 e que instituiu o registro dos bens imateriais nos livros conforme abaixo:

I - Livro de Registro dos Saberes, onde serão inscritos conhecimentos e modos de fazer enraizados no cotidiano das comunidades;

II - Livro de Registro das Celebrações, onde serão inscritos rituais e festas que marcam a vivência coletiva do trabalho, da religiosidade, do entretenimento e de outras práticas da vida social; 
III - Livro de Registro das Formas de Expressão, onde serão inscritas manifestações literárias, musicais, plásticas, cênicas e lúdicas;

IV - Livro de Registro dos Lugares, onde serão inscritos mercados, feiras, santuários, praças e demais espaços onde se concentram e reproduzem práticas culturais coletivas. (DECRETO № 3.551 , DE 4 DE AGOSTO DE 2000)

Este caráter dinâmico do bem cultural, que não pretende "congelar" e sim registrar bens que estão sempre em processo de transformação, assim como a própria cultura, é justamente o proposto pelo Ministério da Cultura. Até o momento já foram registrados 38 bens culturais imateriais no Brasil e outros 22 encontram-se em processo de registro dentre os bens registrados catarinenses estão o Ofício dos Mestres de Capoeira e a Roda de Capoeira, e em processo de registro estão a Centenária Procissão do Senhor dos Passos e o Modo de Saber Fazer do Queijo Artesanal Serrano. Entretanto, Roque e Cunha (2014, p.12) destacam as comunidades portadoras como uma das responsáveis pela salvaguarda do patrimônio imaterial, visto que "o cenário que se tem hoje no país é da existência de profundas desigualdades em relação à implementação de políticas públicas de salvaguarda do Patrimônio Imaterial e de consolidação do Sistema Nacional de Patrimônio Imaterial”.

Desta forma, a continuidade do preparo de bens como o pastel de berbigão e tainha escalada coloca-se como uma maneira de preservação do patrimônio imaterial presente nas comunidades locais. Ao seguir com estes pratos nos cardápios de seus restaurantes, Luiz e Zilá apresentam-se como os portadores destas memórias e destes bens imateriais, contribuindo para a manutenção mesmo que não tenha uma regulamentação ou um registro em algum órgão institucional.

Para a Organização das Nações Unidas para a Educação, a Ciência e a Cultura (UNESCO) o patrimônio imaterial (ou intangível) "compreende as expressões de vida e tradições que comunidades, grupos e indivíduos em todas as partes do mundo recebem de seus ancestrais e passam seus conhecimentos a seus descendentes" (UNESCO, 2016, online). Com um maior detalhamento, o texto da Convenção para a Salvaguarda do Patrimônio Cultural Imaterial da UNESCO apresenta a seguinte definição:

\begin{abstract}
Entende-se por "patrimônio cultural imaterial" as práticas, representações, expressões, conhecimentos e técnicas junto com os instrumentos, objetos, artefatos e lugares culturais que lhes são associados - que as comunidades, os grupos e, em alguns casos, os indivíduos reconhecem como parte integrante de seu patrimônio cultural. Este patrimônio cultural imaterial, que se transmite de geração em geração, é constantemente recriado pelas comunidades e grupos em função de seu ambiente, de sua interação com a natureza e de sua história, gerando um sentimento de identidade e continuidade e contribuindo assim para promover o respeito à diversidade cultural e à criatividade humana. (UNESCO, 2003, p.2)
\end{abstract}

Nesse sentido, cabe-nos pensar nas diversas identidades presentes na cidade e na tentativa da indústria do turismo de enfatizar a culinária açoriana num cenário em que outros grupos étnicos também atuaram na história e construíram uma identidade. A Ilha de Santa Catarina, além de abrigar os náufragos, recebeu os bandeirantes vindos de São Paulo no século XVII, as colonizações açorianas a partir do século XVIII e, ainda neste período, vieram os diocesanos, franciscanos, jesuítas e alemães. Ainda citamos a presença dos indígenas, dos povos de origem africana - a maioria pertencente ao grupo Banto - e a vinda posterior de outros grupos espanhóis, italianos, poloneses, libaneses e gregos. Diante desta diversidade é necessário considerar a cultura local como fruto da mistura de diferentes culturas e tradições.

Os dizeres dos entrevistados mostram apenas uma parte dos saberes e fazeres como uma parte da identidade local. Como nos aponta Alessandro Portelli, a História Oral "tende a representar a realidade não tanto como um tabuleiro em que todos os quadrados são iguais, mas como um mosaico ou 
colcha de retalhos, em que os pedaços são diferentes, porém formam um todo depois de reunidos" (PORTELLI apud DELGADO, 2006, p.52). Ou ainda na metáfora utilizada por Sandra Pesavento quando nos diz que "cada cidade é um palimpsesto de histórias contadas sobre si mesma, que revelam algo sobre o tempo de sua construção e quais as razões e as sensibilidades que mobilizaram a construção daquela narrativa" (PESAVENTO, 2007, p.17).

Na perspectiva de Michel de Certeau (2006), a prática de pesquisa na história contemporânea é entendida como particularizada: uma mutação do "sentido" ou do "real" na produção de desvios significativos; a posição do particular como limite do pensável; a composição de um lugar que instaura no presente a figuração ambivalente do passado e do futuro. Nas suas palavras:

Os lugares são histórias fragmentárias e isoladas em si, dos passados roubados à legibilidade por outro, tempos empilhados que podem se desdobrar mas que estão ali antes como histórias à espera e permanecem no estado de quebracabeças, enigmas, enfim simbolizações enquistadas na dor ou no prazer do corpo. (CERTEAU, 2003, p.189)

$\mathrm{Na}$ atualidade, a cidade de Florianópolis está imersa em um mundo globalizado, onde as identidades estão localizadas no espaço e no tempo simbólico, como geografias imaginárias, conforme apontam as reflexões de Stuart Hall (2006). Para este autor, vivemos em uma aldeia global em que a compressão do espaço-tempo resulta que eventos ocorridos em um determinado lugar tenham impacto imediato em outro lugar. Neste sentido, a ideia de pertencimento está relacionada a casa, paisagens, tradições (ligando passado e presente), mitos de origem (projetando o presente no passado), narrativas de nação (indivíduo e eventos históricos). Segundo Hall (2006), as identificações passam a ser globais, com fluxos culturais formados por culturas nacionais, somado a influências externas mediadas pelo mercado global, transformando-se em identidades desvinculadas (flutuantes), em que ocorre uma homogeneização cultural e uma tensão entre o local e o global. E é neste sentido que percebe-se que a ilha não está isolada e recebe influências de seus antepassados, dos novos moradores e dos turistas que entram em contato com a cultura local, seja através da gastronomia ou do convívio com comunidades locais. Assim, os pratos "tradicionais" não tem uma identidade única por estarem mesclados a cada novo saber aplicados ao fazer.

Conforme aponta Michel Maffesoli (2001) a "metáfora do nomadismo" traduz a ideia de que o indivíduo não se resume a uma identidade, ao contrário, este possui identificações múltiplas. A dialética presente no cotidiano marca a errância como fuga e o enraizamento dinâmico como uma ligação com o lugar, resultando numa tensão de "incompletude permanente", em oposição ao estático e ao imóvel, o que ele aponta como um antagonismo paradoxal constante. Entretanto, esta dialética não funciona para os indivíduos que se encontram fechados em si mesmos, sendo necessário romper as barreiras. Ele afirma que na modernidade ao querer ultrapassar os diversos territórios comunitários acabou por exacerbar o território individual e estigmatizou o nomadismo. A dialética enraizamentoerrância é uma distância unida com papéis cada qual em que tem seu lugar na construção simbólica da realidade social. A tensão entre um lugar e não-lugar está presente na estrutura da sociedade, como um desejo por algo que não está ali em uma realidade flutuante ao entender que o território é relativo, sendo o espaço um determinante. Neste paradoxo é que se desperta o imaginário de cada um. A cidade é apontada por Maffesoli como um espaço pleno para viver a multiplicidade de seres que a habitam, sendo seu habitante um nômade de gênero novo.

Podemos pensar o sujeito na cidade a partir do conceito de "multividualidades", conforme proposto por Massimo Canevacci (2010), no qual a identidade do sujeito dialoga com a cidade provocando uma pluralidade e uma multiplicidade de "eus" - um indivíduo singular e plural simultaneamente, sendo considerado um indivíduo com muitas identidades, um "multivíduo" -, com identidades polifônicas e diaspóricas. 
Por fim, a seleção de um bem cultural sempre se faz em um jogo de disputas, seja pela comunidade ou pelo poder público, mas que tem como base uma construção de uma tradição. Dentro desta concepção, pode-se utilizar o termo "tradição inventada", conforme apresentado por Eric Hobsbawm, em que um conjunto de práticas "visam inculcar certos valores e normas de comportamento através da repetição, o que implica, automaticamente, uma continuidade em relação ao passado" (HOBSBAWM, 1997, p.9). Hobsbawm assim diferencia "tradição" e "costume", enquanto a "tradição" tem a característica e objetivo de ser invariável, impondo práticas fixas do passado através da repetição, por outro lado o "costume" não impede as inovações e permite mudanças, por entender que nem mesmo as sociedades tradicionais são tão invariáveis.

As disputas e as construções em torno do que é patrimônio alimentar envolvem a reflexão sobre o que se torna patrimonializável, pois conforme oberva Elena Espeitx "o patrimônio alimentar de um coletivo é uma seleção de uma parte da cultura alimentar a que se atribui certa tradicionalidade" (ESPEITX, 2004, p.195-196). Ao analisarmos a cultura alimentar em Florianópolis percebe-se que a cada dia a preocupação está mais voltada para o mercado turístico, com a criação de festas e ações específicas para este fim.

\section{Gastronomia e turismo em Florianópolis}

Com o crescimento do turismo na Ilha, os pratos como aqueles preparados por Luiz e Zilá foram alçados a pratos típicos da culinária local. Conforme destacado por Rosely Correa dos Santos e Bianca Antonini (2004, p.90-91), a gastronomia típica da Ilha é aproveitada turisticamente, sendo chamada popularmente de culinária açoriana, elabora cardápios que remetem à presença açoriana na localidade e torna a reconstrução dessa presença, através desses pratos típicos, um atrativo para o turismo na cidade.

$\mathrm{Na}$ atualidade percebe-se que a cada dia os mais jovens buscam criar suas próprias receitas, algumas vezes tomando como base um prato tradicional em sua família, mas também pelas novas práticas alimentares inseridas no mundo globalizado. Com isso, identifica-se que muito tem se modificado das receitas tradicionais visando atender aos diversos paladares que chegam à cidade através do turismo.

A professora do curso de Gastronomia do Instituto Federal de Santa Catarina (IFSC), Silvana Graudenz Müller, relata que em visitas realizadas por ela em alguns restaurantes da capital constatou um desconhecimento da cultura culinária local e do próprio fazer. Com isso desenvolveu um projeto junto aos seus alunos para a valorização do patrimônio local.

Eu pedia "tem um prato típico da llha?", "ah, tem, nós temos moqueca, com leite de coco, dendê...". Então tem alguma coisa que não tá bem explicada. Porque aqui não tem leite de coco, aqui não nasce coqueiro, aqui não tem palma, a palma dendê. (...) A gente vem buscando na escola para fazer um trabalho de ver como que a gente pode melhorar isso, passar a ter alguma inovação tecnológica sem tirar a identidade do prato. A própria gastronomia, uma escola de gastronomia, ganha muito quando você pode ensinar identidade e a história através da comida. ${ }^{11}$

Na última década, a gastronomia passou a ter um novo enfoque, utilizando os recursos naturais disponíveis e desenvolvendo estudos para o crescimento da maricultura ${ }^{12}$ que projeta a cidade como grande produtora nacional de ostras e mexilhões, representando $80 \%$ no mercado nacional, com uma capacidade de produção de 3,2 mil toneladas por ano. Em Santa Catarina, a principal espécie de ostra cultivada não é nativa da região e sim de origem japonesa, ou do Pacífico (Crassostrea gigas), introduzida a partir de estudos feitos no final da década de 1980 pela Secretaria de Agricultura do

\footnotetext{
11 Entrevista realizada em 2010 por Gisele Palma Moser e Daniela Xikota para a elaboração do vídeo documentário "Sabores da Tradição: modos de fazer na gastronomia da Ilha de Santa Catarina" como parte integrante do estudo da disciplina de Patrimônio Cultural, do curso de História, da Universidade do Estado de Santa Catarina (Udesc).

${ }^{12}$ A maricultura trata-se do cultivo de organismos marinhos, atividade que vem crescendo devido à aplicação de novas técnicas e apresentando-se como uma fonte de renda alternativa à pesca artesanal - que se encontra em declínio frente à pesca industrial.
} 
Estado, através da Empresa de Pesquisa Agropecuária e Extensão Rural de Santa Catarina (EPAGRI), e pelo Laboratório de Moluscos Marinhos (LMM), da Universidade Federal de Santa Catarina (UFSC).

Com o crescimento da cidade concomitante à produção da maricultura, um dos fatores que preocupa e que interfere na qualidade dos moluscos é a poluição, podendo afetar o cultivo e a saúde do consumidor, visto que muitas habitações não possuem canalizações corretas de seus esgotos e ainda despejando-os no mar (BECKER, 2008). Assim, a preservação do meio ambiente está na pauta das discussões dos órgãos envolvidos no desenvolvimento do cultivo na capital catarinense. Entre os riscos de poluição, a biológica é a que requer maior atenção, sendo as principais fontes de contaminação a partir de efluentes domésticos e dejetos agrícolas lançados sem tratamentos (WOLFF, 2007 , p.166). Hoje, as comunidades produtoras de ostras em Florianópolis concentram-se no Sul da ilha, sendo a maior no Ribeirão da Ilha, seguida pelas do Norte, em Santo Antônio de Lisboa, Cacupé, Sambaqui e Praia do Forte (SANTA CATARINA, 2013).

Em busca de uma efetividade da atividade de maricultura e de ampliação do mercado para os produtores, em 1999 foi criada a FENAOSTRA Festa Nacional da Ostra e da Cultura Açoriana. Realizada anualmente, sob a organização do Instituto de Geração de Oportunidades de Florianópolis (IGEOF), a festa conta com ampla divulgação da prefeitura, que em sua página na internet diz: "O festival é um verdadeiro resgate da gastronomia e da cultura açoriana da Ilha de Santa Catarina". A afirmação torna-se contraditória diante da presença do cultivo de uma ostra que não é nativa da região e da produção recente somente após o declínio da pesca.

Com a ampliação da maricultura, os pratos típicos servidos nos restaurantes da cidade, junto à tainha escalada e ao pastel de berbigão, incorpora-se uma "nova tradição", como as ostras servidas ao bafo, gratinadas ou cruas e, embora não fosse um patrimônio alimentar local, vai se incorporando aos sabores e fazeres culinários locais. Zilá comenta, apontando para a janela da cozinha que fica de frente para o mar, que aquelas pedras na beira do mar eram cobertas de ostra e afirma: "a gente foi criada comendo essas ostras da pedra". Ou seja, nas comunidades tradicionalmente não tinha um preparo especial para o consumo da ostra. Eram consumidas in natura ou apenas cozidas até a abertura da casca.

A construção de uma nova imagem da cidade, com a valorização dos usos econômicos do patrimônio cultural e a espetacularização do espaço urbano, surge como uma estratégia para a valorização da cidade e impulsão para o mercado turístico. Pensando de acordo com o que propõe Andreas Huyssen, "a imagem da cidade propriamente dita torna-se central para seu sucesso em um mundo globalmente competitivo" (HUYSSEN, 2000, p.100). O city marketing passa a ser utilizado como um instrumento das políticas públicas, no qual a representação do espaço passa a mostrar uma imagem ideal da cidade, transformando-a em mercadoria e atuando diretamente nos processos de intervenção para a renovação urbana (SÁNCHEZ, 2001, p.34).

Em Florianópolis, tal instrumento tem se desenvolvido no intuito de atrair novos moradores com maior poder aquisitivo e investidores para as áreas de potencial turístico. Nesse rol, figuram os empreendimentos gastronômicos, que a fim de enfatizar a vertente identitária fazem uso de emblemas como típico, étnico, da terra e tradicional, transformando os alimentos em artigos de consumo cultural.

\section{Considerações finais}

Como vimos, a cultura alimentar presente na cidade de Florianópolis está centrada nos produtos de origem marinha, devido as suas características geográficas, em um território insular, e aos investimentos feitos para o desenvolvimento da maricultura, colocando a cidade como a principal produtora de ostras e mexilhões para o mercado 
nacional. Entretanto, percebemos que a diversidade cultural desde as primeiras colonizações também agregaram para as alterações nos saberes e fazeres culinários, assim como na atualidade o mercado turístico favorece 0 incremento dos pratos considerados tradicionais.

As narrativas de Luiz, Ana Ester e Zilá permitem perceber os modos de saber e fazer ensinado por seus antepassados, retratando um modo de vida dos moradores locais. Os pratos por eles apresentados são registros de um patrimônio imaterial que ainda permanece vivo. Assim como as mudanças que sofreram no processo do fazer caracterizam um bem em transformação, transmitido de geração em geração através do convívio no fazer e do saber por meio de uma cultura oral. A partir das memórias podemos conhecer estes alimentos e o preparo dos pratos conforme criados e ensinados pelos mais antigos, o que permite compreendermos a cidade e da sociedade onde estes são desenvolvidos.

O que chama a atenção é a forma como estas tradições vêm sendo utilizadas para o turismo. Aos tradicionais pratos de tainha escalada servida com pirão d’água e pastel de berbigão se incorporam outros sabores e gostos que passam a fazer parte da culinária local. O inventário desses sabores e fazeres culinários, bem como a tentativa de fazer deles uma nova tradição culinária, como é o caso da ostra e das festas para promover o seu consumo e criar uma identidade local para o prato, expressam como na construção das tradições as políticas públicas e os interesses voltados ao turismo contribuem para reinventar patrimônios alimentares.

\section{Referências}

BECKER, Daniella de Sousa Maria. Diagnóstico da produção de moluscos no município de Florianópolis/SC. 2008. 121 f. TCC (Graduação) Curso de Ciências Econômicas, Universidade Federal de Santa Catarina (UFSC), Florianópolis/SC, 2008.

BELEM, Fabiana Rodrigues. Do seixo ao zoólito: a indústria lítica dos sambaquis do sul catarinense. Dissertação de Mestrado. Programa de PósGraduação em Arqueologia do Museu de Arqueologia e Etnologia da Universidade de São Paulo. São Paulo, 2012. Disponível em:
<www.teses.usp.br/teses/disponiveis/71/.../tde.../Diss ertBelem2012Errata.pdf>. Acesso em 01 jun. 2015.

BRASIL. Artigo 216 da Constituição Federal Brasileira de $1988 . \quad$ Disponível em: <http://portal.iphan.gov.br/uploads/legislacao/Constitui cao_Federal_art_216.pdf>. Acesso em 07 jan 2016.

BRASIL. Decreto no 3.551, de 4 de agosto de 2000. Institui o Registro de Bens Culturais de Natureza Imaterial que constituem patrimônio cultural brasileiro, cria o Programa Nacional do Patrimônio Imaterial e dá outras providências. Diário Oficial da União. Brasília, DF, 5 ago. 2000. Disponível em: <http://www.planalto.gov.br/ccivil_03/decreto/D3551.h tm>. Acesso em 3 mar. 2016.

CANEVACCI, Massimo. Metrópole comunicacional: a comunicação visual entre corpos e metrópole. Oficina Teórica. Museu Victor Meirelles: Florianópolis, 2010.

CERTEAU, Michel. A invenção do cotidiano: artes de fazer. Petrópolis: Vozes, 2003.

CERTEAU, Michel de. A operação historiográfica. In: A escrita da história. 2 ed. Rio de Janeiro: Forense Universitária, 2006, p.65-119.

DELGADO, Lucilia de Almeida Neves. História Oral: memória, tempo, identidades. Belo Horizonte: Autêntica, 2006.

ESPEITX, E. Patrimonio alimentario y turismo: una relación singular. Pasos: revista de turismo y patrimonio cultural, 2(2), 2004, p.193-213.

HALL, Stuart. Globalização. In: A identidade cultural na pós-modernidade. 11 ed. Rio de Janeiro: DP \& A, 2006, p. 67-76.

HERBST, Danielli Firme. Conhecimento ecológico local dos pescadores do litoral de Santa Catarina sobre a tainha Mugil liza Valenciennes 1836 (Osteichthyes, Mugilidae). Dissertação de Mestrado. Programa de Pós-Graduação em Ecologia da Universidade Federal de Santa Catarina. Florianópolis, 2013. Disponível em: $<$ https://repositorio.ufsc.br/bitstream/handle/12345678 9/106876/318986. pdf? sequence $=1$ \&isAllowed $=y>$. Acesso em 01 jun. 2015.

HOBSBAWM, Eric. Introdução: a invenção das tradições. In: HOBSBAWM, E. RANGER, Terence. A invenção das tradições. Rio de Janeiro: Paz e Terra, 1997.

HUYSSEN, Andreas. Seduzidos pela memória. Rio de Janeiro: Aeroplano, 2000

MAFFESOLI, M. O Território Flutuante. In: Sobre O Nomadismo. Vagabundagens

Pós-Modernas. Rio de Janeiro: Record, 2001, p. 75104.

MURR, Victoria Namestnikov Ell. Langsdorff e Santa Catarina. In: SILVA, DGB., org., KOMISSAROV, BN., 
et al., eds. Os Diários de Langsdorff [online]. Translation Márcia Lyra Nascimento Egg and others. Campinas: Associação Internacional de Estudos Langsdorff. Rio de Janeiro: Editora FIOCRUZ, 1997.

PESAVENTO, Santa Jatahy. Cidades visíveis, cidades sensíveis, cidades imaginárias. Revista Brasileira de História, vol. 27, n 53, junho de 2007, p.11-23.

ROQUE, Lucas; CUNHA, Maria Helena. Sistema nacional de Patrimônio imaterial: conquistas e desafios. In: Patrimônio Imaterial: fortalecendo o Sistema Nacional. Instituto do Patrimônio Histórico e Artístico Nacional. Brasília: IPHAN, 2014, p.10-16.

SÁNCHEZ, Fernanda. A reinvenção das cidades na virada de século. Revista de Sociologia e Política, Jun. 2001, no 16, p.31-49.

SANTA CATARINA. Síntese Informativa da Maricultura 2013. Florianópolis: Empresa de Pesquisa Agropecuária e Extensão Rural de Santa Catarina Epagri, Secretaria de Estado da Agricultura e da Pesca, 2013.

SANTOS, Roselys Correa dos; ANTONINI, Bianca Oliveira. La gastronomia típica de la isla de Santa Catarina - Brasil: su identidad como atractivo para el turismo cultural. Estudos y perspectivas en turismo, vol.13, 2004, p.89-110. Disponível em: <http://unesdoc.unesco.org/images/0022/002277/227 771POR.pdf>. Acesso em 31 mar. 2016.

UNESCO. Convenção para a Salvaguarda do Patrimônio Cultural Imaterial, Paris, 17 de outubro de 2003. Brasília, 2003. Disponível em: <http://unesdoc.unesco.org/images/0013/001325/132 540POR.pdf>. Acesso em 31 mar. 2016.

UNESCO. Patrimônio cultural imaterial. Representação da Unesco no Brasil. Disponível em: $<$ http://www.unesco.org/new/pt/brasilia/culture/worldheritage/intangible-heritage/>. Acesso em 31 mar. 2016.

WOLFF, R. Á. Avaliação de parâmetros oceanográficos em áreas de produção de ostras nas águas da baía Sul (SC) - Brasil. 244 f. Tese (Doutorado) - Curso de Geografia. Universidade Federal de Santa Catarina, 2007. Disponivel em: <https://repositorio.ufsc.br/handle/123456789/103181 >. Acesso em: 23 out. 2015. 